\title{
LA NUEVA NORMALDAD: UN DEBATE EPISTEMOLÓGICO EN TORNO AL PROCESO DE ADAPTACIÓN DEL MUNDO CULTURAL A LA PANDEMIA DE LA COVID-191
}

THE NEW NORMALCY: AN EPISTEMOLOGICAL DEBATE AROUND ADAPTATION PROCESS OF THE CULTURAL SECTOR TO THE COVID-19 PANDEMIC

Estela Alarcón Rodríguez Universidad Rey Juan Carlos, España ORCID: 0000-0001-0122-1652 estela.alarcon@urjc.es

\section{(i) (8)}

\section{Presentación al debate |}

Desde el punto de vista ontológico nos planteamos si nuestro ser, su existencia y su realidad están definidos en una situación de crisis sanitaria mundial, y cómo se va a desenvolver y relacionar en esta nueva realidad en la que se encuentra insertado. Ha de tenerse en cuenta que esta situación extrema nos ha llevado a una sociedad centrada en las experiencias vividas a través de la incesante búsqueda de una adaptabilidad adecuada a esta "nueva normalidad".

El 29 de abril del pasado año, fue el bailarín, coreógrafo y docente Gregory Vuyani Maqoma quien pronunció el Mensaje Internacional del Día Internacional de la Danza. De él se desprende un deseo positivo según el cual la danza ayuda a paliar todas las secuelas que está ocasionando la crisis sanitaria, en la que aún nos encontramos.

Estamos atravesando tragedias inimaginables en un tiempo que mejor podría describir como la era post humana. Más que nunca necesitamos bailar con un propósito para recordar al mundo que la humanidad todavía existe.

La pandemia ha traído consigo unas consecuencias humanas muy graves que se están poco a poco intentando solventar con la deseada vacuna. Conscientes del importante impacto psicológico, la cultura y los artistas, a través de su adaptada creación, producción y difusión del arte, han intentado ayudar a sobrellevar esa tristeza e incertidumbre que nos ha provocado la COVID-19 y que nos hace comprender lo vulnerable que es el ser ontológico que cada uno de nosotros somos. Tanto es así que, durante el confinamiento, la Unesco creó los hashtags \#ComparteCultura y \#ComparteNuestroPatrimonio para poder acceder de forma virtual al patrimonio 
cultural vivo e inmaterial, acercando a todos los ciudadanos hasta sus casas la Cultura y el Patrimonio.

La importancia que se ha dado al consumo de la cultura y las artes durante el confinamiento ha sido considerablemente incrementada. En contraposición, el parón cultural y artístico que han sufrido las personas que conforman estos gremios ha sido y es una constante.

Studia Humanitatis Journal se hace eco de la vital importancia de no dejar de lado el aspecto saludable que la cultura y las artes han generado en las familias y lo que les ha ayudado a poder afrontar el día a día contra la enfermedad. Se implementa por ello, este debate desde un enfoque participativo y activo entre los intervinientes, a partir del relato de experiencias personales y colectivas del sector cultural durante este tiempo de impacto inimaginable.

Con el ánimo de suscitar el debate en torno a los desafíos de este cambio, se ha llevado a cabo una investigación cualitativa basada en el análisis reflexivo desde una perspectiva de la investigación experimental de tres investigadores de prestigio dentro del ámbito de la cultura y las artes.

Ana Colomer Sánchez es Doctora en Arte por la Universidad Rey Juan Carlos, forma parte del grupo de Investigación Nebrija en Comunidades artísticas y académicas, participa en congresos y conferencias nacionales e internacionales, contribuye en comités científicos de varias revistas indexadas a nivel nacional e internacional y publica en revistas de impacto incluidas en Web of Science (SSCl) y Scopus, así como es autora de libros y capítulos sobre la metodología de la investigación y la creatividad, sus líneas de investigación: creatividad, danza, pedagogía.

En su intervención en el debate ha optado por reflejar la visión que ha vivido, dentro del mundo de la cultura y las artes, en las situaciones en las que se ha visto inmersa con la llegada del confinamiento, además añade las entrevistas de dos personalidades relevantes, la Directora de Cultura y Patrimonio de la Generalitat Valenciana, y escritora, Carmen Amoraga y el Catedrático de pintura José María Albareda, que refuerzan su relato.

Rosa Suárez Muñoz es Doctora en Ciencias de la Educación por la Universidad de Granada, es funcionaria de Carrera del Cuerpo de Profesores de Música y Artes Escénicas, y pertenece al grupo de investigación "Didactic and innovation in education and physical sport activity” (HUM-979 d-i-epsa).

Durante más de quince años, Suárez Muñoz ha realizado proyectos de innovación educativa con el arte y la cultura como vehículo de aprendizaje. Con esta experiencia, su contribución al debate se centra en la educación y la cultura en tiempos de pandemia, particularmente cómo se han adaptado las actividades programadas en educación y cultura en Granada a las limitaciones suscitadas por la pandemia.

Manuel Garzón Albarrán es Licenciado en Coreográfica e Interpretación de la Danza, se forma en el Royal Ballet de Londres, en el Ballet del Teatro Alla Scala de Milán y la Scuola 
di danza, Teatro dell'Opera di Roma. Lleva 15 años compaginando su carrera de intérprete de danza con la docencia y la coreografía, colaborando con varias compañías de danza nacionales y participando como bailarín y coreógrafo en reconocidos festivales internacionales como Festival Internacional de Ballet de la Habana (Cuba), Encuentro Nacional de Danza Contemporánea de Río Grande del Norte (Brasil), Festival de Invierno de Campiña Grande (Brasil), Festival Internacional de Danza de Miami, Festival Internacional de Danza de Santo Domingo (República Dominicana).

Su línea de investigación se centra en los procesos creativos en danza y el papel de las emociones en la creación. $\mathrm{Ha}$ intervenido como comunicador en varios seminarios internacionales de investigación científica como la Russian State University "A.N. Kosygin" (Rusia), Vaganova Ballet Academy (Rusia) y Faculty of Arts and Humanities of Universidade de Coimbra (Portugal), entre otros; exponiendo investigaciones sobre la matriz de la Historia de la Danza y la composición coreográfica.

Su contribución en el debate sigue la línea de sus investigaciones, presentándonos el proceso creativo que ha realizado durante el confinamiento, el modo en que ha trabajado con el movimiento y el cuerpo físico a distancia.

Los tres debatientes presentan unos trabajos impecables en los que dejan para el futuro, un sello a través de los métodos adaptativos que han utilizado para seguir fomentando la cultura y las artes, las cuales han ayudado y ayudarán a combatir todo lo que ha acontecido y todo lo que acontecerá.

\section{Referencias}

Gregory Vuyani, M. (2020) International Dance Day: World Organization for the Performing Arts. Disponible en < https://www.international-dance-day.org/es/idd2020.html >.

Unesco. (2020). Explorar el patrimonio mundial desde casa con la UNESCO. Disponible en < https://es.unesco.org/news/explorar-patrimonio-mundial-casa-unesco $>$.

\section{Nota biográfica}

Licenciada en Pedagogía de la Danza Española por el Conservatorio Superior de Danza María de Ávila de Madrid, Máster en Artes Escénicas en la Universidad Rey Juan Carlos. Doctora en Artes Escénicas por la URJC. Profesora Visitante en al área de Filosofía Moral del Departamento de Humanidades en la URJC.

Inició su actividad investigadora junto al reconocido folclorista Juan José Linares, máximo representante en el mundo de la danza tradicional española, siendo su profesora asistente.

Ha publicado artículos en revistas científicas indexadas que ocupan posiciones destacadas en las bases de datos de referencia en el ámbito internacional (Scopus, ESCl, CARHUS Plus+2018, MIAR, FECYT). 
Tiene diez años de experiencia docente en los Grados Universitarios de Artes Visuales y Danza, y Pedagogía en Artes Visuales y Danza en el Departamento: Ciencias de la Educación, el Lenguaje, la Cultura y las Artes, Universidad Rey Juan Carlos.

Ha sido Directora Académica del I Título de Especialista en Danza Tradicional, Mención Extremadura y del II Título de Especialista en Danza Tradicional, Mención Andalucía en la Universidad Rey Juan Carlos, Madrid.

Es miembro del Grupo de Innovación Docente en Artes Escénicas ARES INNOVA de la URJC, así como del Grupo de Investigación emergente "En el corto siglo XX español: transferencia político-social, cultural y económica en una perspectiva global” CORSIES (URJC). 